\title{
DIRECT CONTROL OF THE 'RETINAL FIELD': REPORT ON THREE CASES. ${ }^{1}$
}

\author{
BY PROFESSOR GEORGE TRUMBULL LADD,
}

Yale University.

In the Psychological Review for July, I894, I gave a brief report of certain experiments made with a view to determine the answer to this question: "Can the sensations customarily called ' retinal,' which arise with the eyes closed and motionless, be made to respond to volition with respect to the form and color which they assume?" These experiments were instituted with a graduate class of sixteen members - all of them entirely capable of conducting and accurately reporting such observations. Of the sixteen only four reported no success; nine had a partial but constantly increasing success; while the remaining three attained speedily to very remarkable results. These three soon found themselves able to determine at will, within the limit set by the experiment, the shape of the visual phenomena; and, as well, the color - the color being sometimes so vivid that, on opening the eyes upon a sheet of white paper the proper complementary after-image promptly appeared.

These phenomena which I then regarded as exceedingly suggestive and, when taken in connection with numerous allied experiences, as necessitating an almost-complete change in our theory concerning the functions of the retina and the relation of visual sensations to centrally initiated conative impulses, have, so far as I am aware, received far less attention that they merit. I have myself been unable to pursue further the investigation. But there have since been handed to me three reports of self-experimentation which I consider well worthy of submitting to the Association, with the remark that they are all by trained students and successful teachers of psychological subjects. In this connection I take the liberty to request the mern-

1 Read before the Amer. Psych. Assoc, Washington, Dec., Igo2. 
bers of the association to assist in future investigation of the problem by kindly sending to me any material which they may be able to collect.

There follows now a report of the cases:

Case 1. - Mr. W. P. M., Harvard' 97 , who repeatedly succeeded with himself in these two classes of experiment which I describe verbatim as given by the experimenter. Experiment 1. : "By closing my eyes somewhat tightly I could see a number of 'bits' of colored light upon my ' retinal field.' Selecting one of these colors I concentrated my attention upon it, and it seemed to grow of its own accord into a perfect circle. I then willed that this circle should become an ellipse; and without the faintest 'muscular sensations' (except the vague strained feeling of purely mental concentration) the circle 'sagged ' into an ellipse; thus

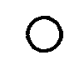

Fig. 1 .

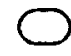

Fig. 2.

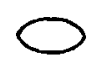

Fig. 3 .

Fig. 3 being exactly the same shape as the ellipse that I had pictured in my mind as the ideal end to be attained, in visible actuality upon my retinal field. This experiment has been successfully and easily performed by me a number of different times."

Experiment II. - "Fixing my attention upon one of the colored circles above mentioned I succeeded by an act of will in changing the color of the ring from blue to red. I have also changed a red ring to a yellow or green, according as I desired. There were no muscle-sensations. Having given the 'fiat' of my will, I would wait quietly, observing the variously colored shapes float fantastically before me until the ring of the old color gave place, as it were of its own accord, to the ring of the desired color. I was not always successful in this experiment; and the length of time which I had to wait was very variable."

Case 2: Mr. H.D., Yale Ph.D., 5896. The tabulated results obtained by this experimenter, which are herewith presented, may be profitably supplemented by the following remarks as given in the language of the subject himself. 


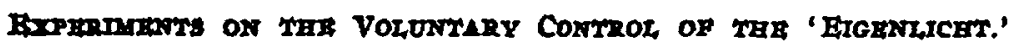

First Series. Experimenter $H . D$.

\begin{tabular}{|c|c|c|c|c|}
\hline No. of 1 periments. & 1. & 2 & 3. & 4. \\
\hline Date. & Nov. 20 & Nov. 81. & Nov. 22. & Dec. 7 . \\
\hline $\begin{array}{l}\text { I. Time taken to produce } \\
\text { cross. } \\
\text { 2. How long it conld be } \\
\text { retained. } \\
\text { 3. Modification of shape. } \\
\text { 4. Modification of color. } \\
\text { 5. Effect of fatigue. }\end{array}$ & $\begin{array}{l}\text { A. M. } 2-3 \text { min. } \\
\text { P. M. I min. } \\
\text { A. M. } 3 \text { sec. } \\
\text { P. M. } 5 \text { sec. } \\
\text { A. M. Several times. } \\
\text { P. M. Bars exteuding. } \\
\text { A. M. Red. } \\
\text { P. M. Red. } \\
\text { A. M. Image blurred. } \\
\text { P. M. " }\end{array}$ & $\begin{array}{l}\text { Same as Rxp. I. } \\
2 \text { sec. } \\
\text { Bars extending. } \\
\text { Red. } \\
\text { Pain back of right eye; } \\
\text { dieappearance of im- } \\
\text { age. }\end{array}$ & $\begin{array}{l}\text { 1//2 min. } \\
\text { About } 20 \text { sec. } \\
2 \text { sec. } \\
\text { Io sec. } \\
\text { Bart extending. } \\
\text { "s " } \\
\text { Deepening red. } \\
\text { Red to whitish gray. } \\
\text { Pain in right eye; same } \\
\text { as to image. }\end{array}$ & $\begin{array}{l}15 \text { sec. } \\
5 \text { sec. } \\
\text { Little change. } \\
\text { Silvery white to red. }\end{array}$ \\
\hline
\end{tabular}

\begin{tabular}{|c|c|c|c|c|c|}
\hline No. of Bxperiment. & 5. & 6. & 7 & 8. & 9. \\
\hline Date. & Dec. 8. & Dec. g. & Dec. 88. & Dec. I9. & Dec. 20. \\
\hline $\begin{array}{l}\text { 1. Time taken to pro- } \\
\text { duce cross. } \\
\text { 2. How long it conld } \\
\text { be retained. } \\
\text { 3. Modification of } \\
\text { ahape. } \\
\text { 4. Modification of } \\
\text { color. } \\
\text { 5. Effect of fatigue. }\end{array}$ & $\begin{array}{l}\text { A. M. } \\
\text { P. M. } 20 \text { sec. } \\
\text { A. M. } \\
\text { P. M. } 7 \text { sec. (clearly). } \\
\text { A. M. } \\
\text { P. M. At } 7 \text { sec. it dis- } \\
\text { A. M. sppeared. } \\
\text { P. M. Red to deeper } \\
\text { A. M. red. } \\
\text { P. M. Fallure of con- }\end{array}$ & $\begin{array}{l}\text { 10 sec. } \\
\text { ro sec. } \\
\text { Cross lost in circle. } \\
\text { Red to silvery gray. } \\
\text { Pain and then fall- } \\
\text { ure of control. }\end{array}$ & $\begin{array}{l}\text { 5-10 sec. } \\
\text { I2 aec. } \\
\text { Control of shape } \\
\text { lost. } \\
\text { Red deepening. } \\
\text { Deepening and ver- } \\
\text { tigo. }\end{array}$ & $\begin{array}{l}\text { I min. } \\
\text { Io sec. } \\
5 \text { pec. } \\
\text { Bars extending. } \\
\text { Bars extending. } \\
\text { Vertigo and oblit. } \\
\text { eration. }\end{array}$ & $\begin{array}{l}20 \text { sec. } \\
\text { A bout } 7 \text { sec. } \\
\text { Vertigo set in and } \\
\text { cross is lost. } \\
\text { Vertigo set in and } \\
\text { cross is lost. } \\
\text { Vertigo set in and } \\
\text { cross is lost. }\end{array}$ \\
\hline
\end{tabular}


Second Series. Experimenter B. $Z$.

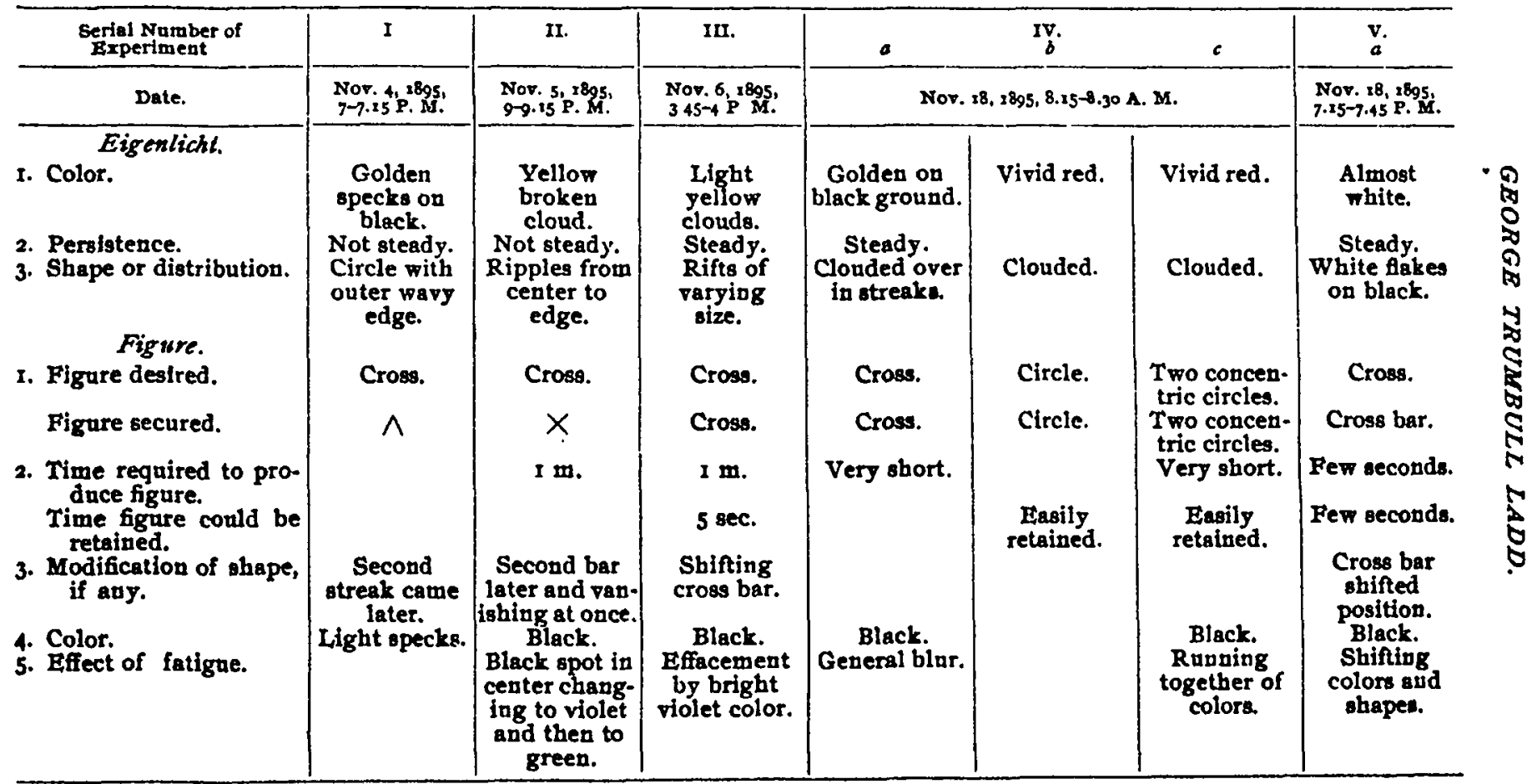


Second Series.-Continued.

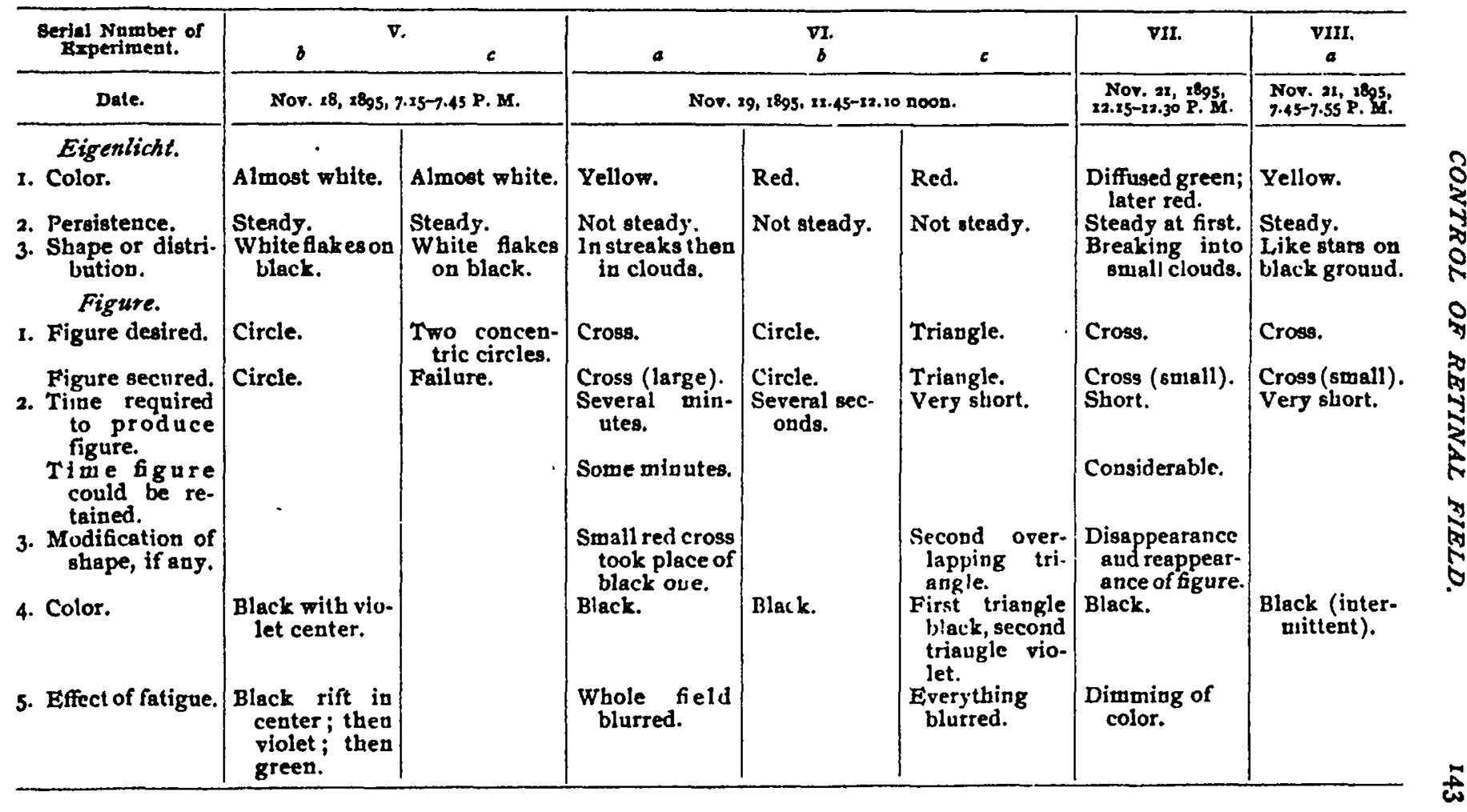


Seeond Series. - Continued.

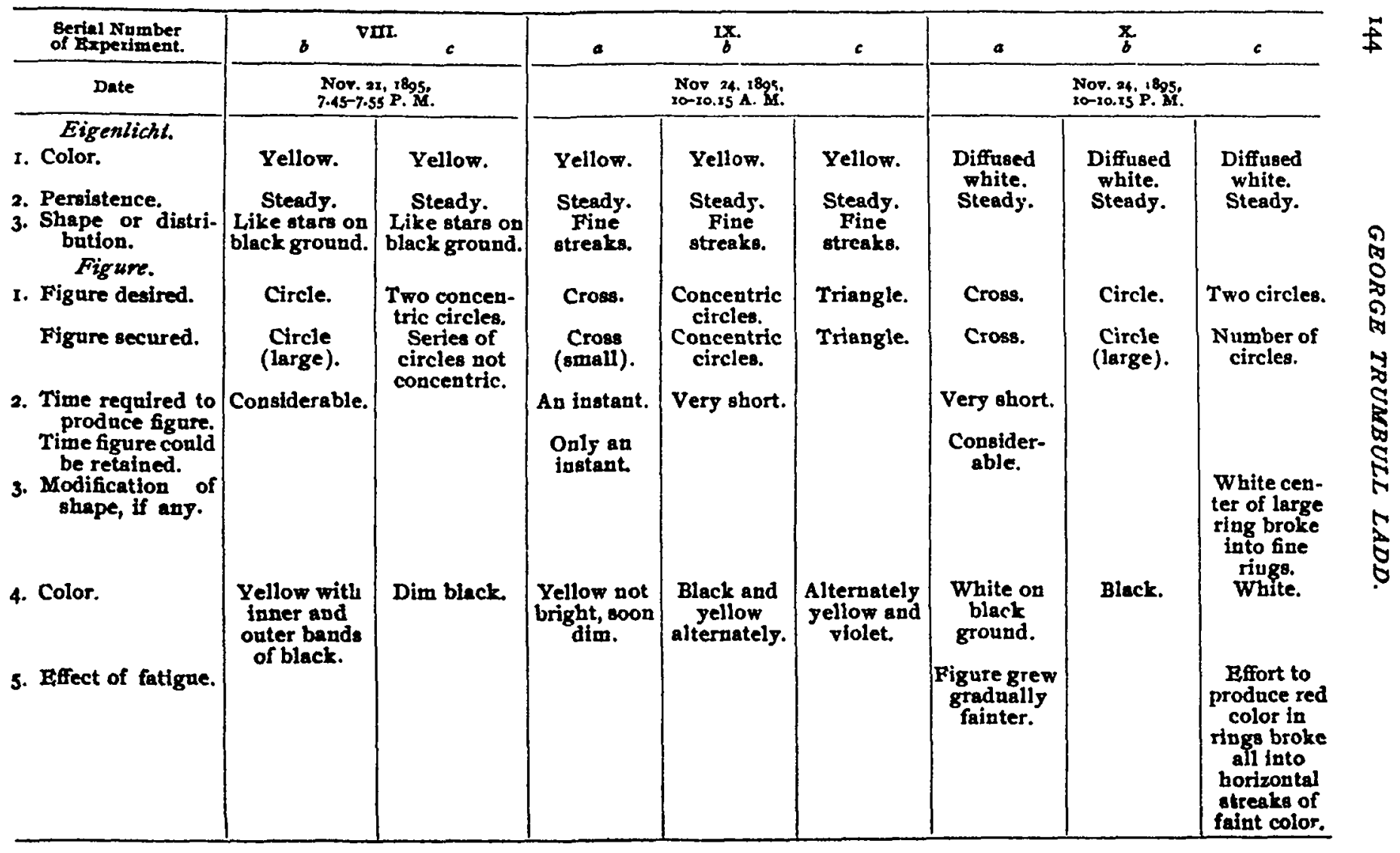


I. "The color of the 'Eigenlicht' had (i. e., ordinarily on beginning the experiment) the appearance of a dancing mass of vari-colored dust, red predominating."

2. "Persistence depended upon the physical conditions, and varied accordingly. " " "The best results have been secured, uniformly, after a long evening's reading, where there has been continued concentration of attention. " " "As $800 n$ as attention and will had gained control of the mass, the color seemed to be at their mercy."

3. "The normal appearance of the 'Eigenlicht' is always round. The center of the circle is the bridge of the nose; the radius extends to the corner of the eye and sweeps over the forehead to the other eye. It seems to be very objective and quite dependent" $-i$. e., on the will.

4. "A triangle is more easy for me to produce than a cross, and a circle easiest of all. " " "Generally the cross was projected, when it came, at once. Thus it seemed to depend upon the creation of the brain."

This experimenter has frequently testified to me that the control of the color of the images obtained in this way is, in his case, usually easy and nearly complete.

Case 3: Miss B. Z., Yale Ph. D., '97. The extended series of experiments presented herewith in tabulated form requires no separate remarks except the observation that, in this case, the control of the subject was exercised over the shape of the visual image. No evidence of marked control over its color is presented.

It is undoubtedly too early in the investigation to draw from it with confidence any extended theoretical conclusions. Certain facts of general import seem, however, to be common to all the cases which have thus far been reported; and, also, certain changes in the current theory of color vision to be at least indicated. I append, therefore, to my two reports of, in all, some fifteen cases the following somewhat tentative observations.

I. It seems obvious that the control of the size and color of the images appearing before the eyes when they are closed in the dark grows by practice. As everywhere else, so also here, trying begets habit; and ease and success accompany the 
growth of habit. This was certainly so in my own case, when I first obtained the phenomena which led me to propose the problem to others. And I am inclined to think that nearly or quite all the instances of failure to get some access of successful results are due to a lack of persistence and of confidence in the possibility of finally succeeding. But here, as in the case of all our uses of the delicate and complex organic mechanism, both peripheral and central, different individuals differ greatly in their native and acquired aptitudes.

2. It is not as yet quite clear how much of the effect must be ascribed to a selective attention, somewhat resembling that with which we watch for, seize upon, and hold in consciousness a word which we will to recall. I am, however, entirely confident that the phenomena cannot be completely accounted for in this way. An exalted, not to say abnormal activity of the color sensations is undoubtedly favorable to obtaining the best results. In my own case, when I was excited and somewhat hyperæsthetic, my experiments were most startling as respects the success attained. Such a condition affords, as it were, an increased abundance of material upon which selective attention may be directed. Yet many of the responses made to the will appear to be almost as prompt as those which concern changes in some portion of the motor organism. Nevertheless, -

3. The testimony of all seems to be perfectly conclusive that the desired results as to the size and color of the images cannot be wholly mediated by the motor apparatus connected with vision by the eye. A certain feeling of strain, such as goes with intense attention to a visual object, is, indeed, a common accompaniment of the first efforts to obtain a circle, cross, or triangle. One is also usually conscious of focusing the eye upon this object. And pain in the eyeball, or back of it, frequently follows prolonged experimentation of this sort. Squeezing the eyeball with its own muscular surroundings may result in an increased liveliness of the color sensations. But unconscious and minute movements of the eye can scarcely be beld to account for the appearance of the particular shape desired; and as to changes of color, I am sure I should not know how to connect any particular voluntary or involuntary 
movement of the eyes with the turning at will of a red cross, or circle, or triangle, into one of green or yellow.

4. These phenomena, especially when considered in connection with numerous others - e. g., certain experiments with color illusions and visual dreams, which I have previously reported to the Association, and other phenomena, which have either been simply observed or more or less thoroughly examined by different students of psychological phenomena - have convinced me that our entire modern theory of vision has gone astray in respect of the functions of nervous elements in the retina. In a word, I believe that the shapes and colors of our visual images are centrally determined to a far greater extent than has hitherto been supposed. In my judgment we shall never find the final physiological explanation of our experience with colors in the structure and functions of the retina. Further investigation of the histology of the rods and cones, or of the functions of the two, or of the services rendered by various pigments in conjunction with the retina, will probably not add further knowledge as to the nature or causes of the psychical phenomena. Physical and physiological or chemical theories of the retinal functions are of comparatively little value for the psychology of vision. The fusion, the differentiation, the contrast, the sequence of our color sensations, depend upon complex cerebral processes, the nature of which is determined, not simply by the quality and intensity of the stimuli and by the effect of the stimuli upon the peripheral organism, but also in large measure by the associations and habits of those nervous centers of the brain that are correlated with the other senses and with memory, recognition, attention and choice.

The proof that a more 'central' theory is needed to account for our experience with visual images even of the more simple sort, their shapes and their colors, and that the influence of the retinal elements and their functions has been hitherto greatly overestimated, is by no means confined to phenomena such as I have just described. The remarkable color illusion to which I called attention in the 'Studies from the Yale Psychological Laboratory' in 1898 , and color illusions in general, point in the same direction. So also do the phenomena 
of 'color audition' which, if under this term we include the excitation of color sensations by auditory stimuli, are much more frequent than is ordinarily supposed. An example taken from my own experience will be of interest here. Several years ago I was having some floors in my house scraped with a metal tool in order to prepare them, by removing the old filling and wax, for being filled and waxed anew. I had several times during the noon hour amused myself by using this tool, thus establishing fusions between the sensations of sound which the tool produced and the changed and streaked colored appearance of the floor at which I was gazing intently as I worked. After this preparation of the brain, as I was lying with closed eyes on the bed in the room above, waiting for my vacation afternoon nap, the sounds of the tool used by the workman in the room below promptly and invariably stimulated in the so-called 'retinal field' the visual images of the streaks in the floor, varied nicely so as to correspond with the variations of the auditory stimuli. That is to say, when I heard the sounds of scraping, I at once saw before the eyes the same streaks which my experience had previously fused with precisely similar sounds of scraping.

It is a very common experience with me - and I find on inquiry also with others - to have the fainter or more vivid but appropriate visual images start out in the retinal field, when the eyes are closed on occasion of certain skin or muscular sensations being started; or even when, as we say, thinking vaguely and perhaps dreamily ' about' kinds of transactions that readily admit of schematic visualization. Now these are certainly forms of stimulating the production, and determining the color and shape of visual images, that have nothing whatever to do with the nervous elements or the pigments of the retina. The voluntary control of the way in which colored images shall be stereoscopically united points in the same direction. If one prepares two squares of paper of the same size, but of different colors, persistent practice to obtain control, in many cases, enables one at will, when the two squares are stereoscopically united, to see the combined image with either one of the two colors, or to fuse them in the color which is itself 
the mixture of the two. Such experiences, I repeat, go a long way toward relieving us from the necessity of any further effort to find in the structure and functions of the retinal elements or in the chemical constitution of the pigments of the retina the account of color sensations, and of the phenomena of their fusion, contrast, and differentiation.

5. I shall perhaps seem to most of you to be extending unwarrantably the conclusions based upon this entire class of facts, if I say that they seem to me to bear important testimony to a certain theory of consciousness and of the nature of man's mental life and mental development. I admit at once, of course, that were these facts left standing alone the charge of gross exaggeration of their importance would be justified. But they are not alone. They are only one group of facts - of countless thousands in numbers and classifiable under a score or more of heads - which, in a way quite satisfactorily prove the truth of the general theory. Negatively stated, no theory, sensational, associational, physiological, or psycho-physical, which regards consciousness merely 'content-wise' and passively, can adequately account for even the simplest of our experiences. Positively stated, consciousness must from the very first and in all its varied forms of manifestation be considered as an active, discriminating, selective, and directive force. Only from this point of view can we explain the evolution of the so-called higher faculties of the mind. This energistic aspect of consciousness, this general faculty which is needed to account for the formation of all the particular so-called faculties of man, is everywhere present for the working psychologist to discover and to trace its historical development, in the individual and in the race. Admitting this theory, more or less of direct control over the shapes and colors of objects appearing in the so-called retinal field seems consistent enough with all that we know about both cerebral physiology and also mental life, from the psychologist's point of view, which is the standpoint of consciousness. 